\title{
O ROMANCE CACAU, DE JORGE AMADO, COMO ESPAÇO DE DENÚNCIA E MEMÓRIA DE UM DETERMINADO MOMENTO HISTÓRICO
}

\author{
Caroline dos Santos Gomes \\ Mestranda em Estudos Literários pela UERJ \\ carolinedsgomes@gmail.com
}

\section{RESUMO}

Este trabalho apresenta o romance Cacau, de Jorge Amado, enquanto espaço de recordação e denúncia de um momento histórico, propondo uma análise crítica sobre o compromisso da escrita literária em comparação com a historiográfica. Para a revisão teórica, são utilizados os textos de Seligmann-Silva, Gagnebin, Jauss, Piglia, Koselleck, entre outros. Também são apresentadas breves considerações sobre o autor e seu projeto político, visto que o mesmo mostrou significativa participação nesse campo, refletindo, em suas obras, suas concepções políticas e sociais.

Palavras-chave: Memória. Cacau. Jorge Amado.

\begin{abstract}
This article presents the novel Cacau, by Jorge Amado, as memory space and denouncement of a historical period, proposing a critical analyze about the commitment of literary's write in comparison with the historiographical. For theoretical revision, Seligmann-Silva, Gagnebin, Jauss, Piglia, Koselleck, and others texts are used. Also, brief considerations about the author and your political project are presented, insofar as him demonstrate significant participate in this area, reflecting, in your works, your political and socials conceptions.
\end{abstract}

Keywords: Memory. Cacau. Jorge Amado.

INTRODUÇÃO:

Peço então que me citem um só bom romance cujo o propósito expresso seja o de servir à opressão [...].

Jean-Paul Sartre

A epígrafe acima, de Jean-Paul Sartre, pertence ao segundo capítulo, intitulado de

Por que escrever?, da obra Que é a Literatura?. No capítulo, Sartre propõe reflexões sobre as 
diversas razões para que um artista decida empenhar-se em uma obra, como fuga ou conquista. Posteriormente, menciona que a existência humana não é essencial para a continuidade da Terra e conclui, portanto, que "um dos principais motivos da criação artística é certamente a necessidade de nos sentirmos essenciais em relação ao mundo." (SARTRE, 2004, p. 34). A partir dessa afirmação, o que pretende-se nesse trabalho é examinar o compromisso ético da literatura, especificamente do romance Cacau e suas respectivas denúncias, propondo uma análise crítica sobre qual é o papel da escrita literária em contraponto com a historiográfica.

Para tanto, serão utilizadas as teorias de Seligmann-Silva, Gagnebin, Jauss, entre outros, para a definição de historiografia e para contemplar a forma literária. O romance Cacau será analisado, bem como o projeto político de Jorge Amado. O que questiona-se, afinal, é como a literatura se relaciona com a noção de revolução? Como pode plasmar algo no mundo? Qual é o papel da mesma em produzir efeitos de verdade a partir da ficção?

\section{A HISTORIOGRAFIA E A LITERATURA:}

Seligmann-Silva, (2006, p.67), faz um recorte de teorias que abordam a história como um campo de neutralidade em que "nega-se estrategicamente a interação entre memória e historiografia."

O teórico afirma que a memória, como forma mais efetiva de relacionamento com o passado, intervém na historiografia, até então considerada neutra. Desse modo, enfatiza que, no quesito ética da representação, temos uma dívida com o passado e com os mortos, entretanto, "é evidente que não existe a possibilidade de uma tradução total do passado." (ibidem, p.64). 
Nesse sentido, Seligmann-Silva questiona a teoria conservadora de separação entre o trabalho da história e o da memória, já que, de acordo com ele, isso não pode acontecer de maneira total. Para tanto, coloca à prova a hipótese de que um historiador judeu, por exemplo, deveria abdicar de tratar de temas relacionados ao Holocausto, concluindo que

não existe um sujeito desinteressado no seu tema. No campo da História e sobretudo da História que se debruça sobre o passado mais recente, seria inocente postular a existência de tal esfera de total objetividade. (SELIGMANN-SILVA, 2006, p. 68).

O autor defende, citando Nietzsche, que a historiografia torna-se fria e imparcial por tentar arquivar um aspecto totalitário dos acontecimentos, quando o registro da memória é seletivo e opera entre lembrança e esquecimento. O que propõe, então, é que na dicotomia História e memória um não deva apagar o outro, mas amparar-se mutuamente a fim de evitar

a violação brutal daquilo que a memória ainda pode conservar, da mentira deliberada pela deformação das fontes e dos arquivos, da invenção de passados recompostos e míticos a serviço de poderes tenebrosos. (YERUSHALMI apud SELIGMANN-SILVA, 2006, p.62).

Conclui, então, que, "ao que tudo indica, estamos despertando desse sonho ou pesadelo - recorrente - do historicismo, que acreditou na possibilidade de se conhecer o passado 'tal como ele de fato ocorreu'". (SELIGMANN-SILVA, 2006, p.60).

Assmann, (2006, p.15), aborda a teoria de Koselleck de que

a história deve primeiro estar morta nas mentes, nos corações e nos corpos das pessoas afetadas, para que possa então ergue-se como ciência, tal qual uma fênix a partir das cinzas da experiência. Enquanto houver pessoas afetadas pela lembrança e, com elas, afecções, reivindicações e protestos concretos, a perspectiva científica corre risco de distorção. 
Portanto, objetividade não é uma questão de método e de padrões críticos, mas também de mortificação, extinção e desvanecimento da dor e da consternação.

Essa teoria vai diretamente de encontro do que Seligmann-Silva tanto criticou em seu texto: a impossibilidade de afastamento entre memória e História. A literatura também trabalha na potência oposta a que foi proposta por Koselleck: a partir da "extinção e desvanecimento da dor e da consternação" (KOSELLECK apud ASSMANN, 2006, p.15) não há catarse, o que não gera empatia e tampouco a transformação de um determinado meio social, político, entre outros. Embora a Literatura tenha relações com a História, ambas não equiparam-se, visto que espera-se abordagens diferentes da narrativa historiográfica e da narrativa literária.

Por isso, então, é necessário perceber a literatura "como uma oficina de aprimoramento da linguagem enquanto uma máquina não tanto de 'representar' o 'real', mas de dar uma forma a ele." (SELIGMANN-SILVA, 2003, p. 376). Daí o compromisso ético da literatura como lugar de memória e espaço de histórias que se relacionam com uma determinada época: tem o poder de dar a ver o mundo a partir de um artifício, funcionando como lugar para pautas de minorias - como pode-se observar no romance abordado nesse trabalho - e como testemunho a partir de uma estética de representação do irrepresentável. De acordo com Jauss, (1994, p.21),

a função social (da literatura) somente se manifesta na plenitude de suas possibilidades quando a experiência literária do leitor adentra o horizonte de expectativa de sua vida prática, pré-formando seu entendimento do mundo e, assim, retroagindo sobre seu comportamento social. 


\section{O PROJETO POLÍTICO DE JORGE AMADO:}

Jorge Amado viveu entre os anos de 1912 e 2001 e desenvolveu significativa atuação no campo político e intelectual. Experienciou o Estado Novo (1937-1945) e a Ditadura Militar (1964-1985), no Brasil. Além disso, relacionou-se com a Ditadura Soviética, bem como os regimes autoritários em Cuba e Portugal. ${ }^{1}$

O autor era um membro engajado do Partido Comunista e sua vida política o levou a ser detido em 1936, posteriormente à Intentona Comunista. Entretanto, seu relacionamento com o regime autoritário começou antes: Cacau foi censurado em 1933, mas Amado conseguiu sua publicação com a ajuda de amigos, vendendo dois mil exemplares em quarenta dias.

Jorge Amado sofreu constante vigilância do governo. Perdeu seu emprego, foi preso, exilado, seus livros foram recolhidos e a venda foi proibida no Brasil.

Participou da campanha de eleição para presidência de José Américo de Almeida, em 1937, mesmo ano em que Getúlio Vargas implantou a ditadura do Estado Novo. O escritor foi detido novamente e quase dois mil exemplares de seus livros foram queimados em praça pública.

Amado considera Cacau como um romance proletário. Vieira e Silva, (2012, p.61), mencionam as diferentes abordagens desse tipo de romance: numa classificação ampla, inclui produções, filiadas ou não ao Partido Comunista, que são simpáticas às causas trabalhadoras. Já numa classificação restritiva, são obras de autores filiados ao partido e que manifestam os pontos de vista do mesmo. Jorge Amado afirma que

\footnotetext{
${ }^{1}$ Informações retiradas do texto "História e memória da trajetória político-intelectual de Jorge Amado, de Carolina Fernandes Calixto. Disponível em: http://www.historia.uff.br/stricto/td/1857.pdf. Acesso em: $22 / 07 / 2017$
} 
Cacau e Suor, que se seguem de muito perto - 1933, 1934 -, significam meu encontro com a esquerda - é o momento em que me torno um militante da esquerda, e meu encontro com a literatura, com o romance proletário dos anos 20 , com a literatura soviética da primeira fase e com os escritores americanos que surgiam. (AMADO apud VIEIRA; SILVA, 2012, p. 62)

Assim, é possível inferir que Jorge Amado depositou em sua obra suas concepções políticas e sociais, atuando em favor do proletariado e fazendo denúncia dos meios de opressão, já que, de acordo com o escritor, Cacau foi escrito "com evidentes intenções de propaganda partidária. Conservei-me, porém, rigorosamente honesto, citando apenas fatos que observei." (AMADO apud VIEIRA; SILVA, 2012, p. 57).

Cabe, ainda, citar o que Sartre considera como compromisso ético do autor:

e se esse mundo me é dado com suas injustiças, não é para que eu as contemple com frieza, mas para que as anime com minha indignação, para que as desvende e as crie com sua natureza de injustiças, isto é, de abusos que devem ser suprimidos. (SARTRE, 2004, p.51).

\section{CACAU, UM ROMANCE DE MEMÓRIA E DENÚNCIA:}

Não há mais aqui nem representação, nem identificação, mas somente uma aproximação atenta daquilo que foge tanto das justificativas da razão como das figurações da arte, mas que deve, porém, por elas ser lembrado e transmitido.

Jeanne Marie Gagnebin

Jorge Amado inicia Cacau com a seguinte epígrafe que reforça sua intenção de filiar o romance às causas do Partido Comunista: "Tentei contar neste livro, com um mínimo de 
literatura para um máximo de honestidade, a vida dos trabalhadores das fazendas de cacau do sul da Bahia. Será um romance proletário?" (AMADO, 2010, I.53).

O par antitético proposto pelo autor - literatura $\mathrm{x}$ honestidade - leva o leitor a refletir sobre uma arte que se quer como real e que, por si só, tem uma natureza ficcional. Por isso, reconfigura o conceito de literatura, já que,

o comprometimento com o 'real' faz com que o autor exija um redimensionamento do conceito de literatura. A relação desse autor com o passado ao qual ele tenta dar uma forma tem o caráter de um compromisso ético. (SELIGMANN-SILVA, 2003, p. 386).

Por isso, de acordo com Vieira e Silva, (2012, p.57),

Amado tentou escrever um romance comprometido com a transformação da sociedade, numa perspectiva que atendia à política do Partido: o intelectual deveria produzir ficção com força de "documento", denunciando a existência de segmentos sofredores da população.

O protagonista de Cacau é conhecido como Sergipano. Ele era filho do dono de uma fábrica, mas, após a morte do pai, seu tio apropriou-se dos negócios de família, fazendo com que Sergipano se tornasse operário da mesma fábrica. Seu tio, entretanto, também era um operário, mas saiu da condição de explorado para explorador, conceito que Amado aborda novamente ao longo da narrativa.

As condições dos trabalhadores da fábrica são expostas por Sergipano, que contrapõe a figura do pai com a do tio: o primeiro fazia questão de conversar com seus funcionários a fim de sanar as queixas feitas por eles. A fábrica estava em harmonia e funcionava com "relativa prosperidade" (AMADO, 2010, I.125). Sergipano aprendeu com o 
pai a ser simpático com as causas operárias antes mesmo de se tornar um. O segundo explorava os trabalhadores o quanto pudesse, até mesmo assediando sexualmente as operárias.

Sergipano menciona que suportou a brutalidade de seu tio por cinco anos, mas foi demitido quando agrediu seu tio após descobrir que o mesmo estava assediando Margarida, a mulher de quem o protagonista gostava. Esse caráter maniqueísta perpetua-se por todo o romance: a dualidade bem e mal são evidenciadas constantemente.

Após sua demissão, o protagonista decide ir ao sul da Bahia para trabalhar na produção do cacau. Consegue, então, um emprego na Fazenda Fraternidade, onde se passa grande parte do romance. Sergipano seria "alugado" do Coronel Mané Frajelo, termo que ele abominava. "O termo me humilhava. Alugado...Eu estava reduzido a muito menos que homem"(AMADO, 2010, I.295). Em outras palavras, o alugado era como um animal ou um maquinário, desprovido de direitos e sem consciência de classe.

Jorge Amado denuncia em Cacau as condições dos trabalhadores nos cacaueiros, bem como sua exploração pelos chamados de coronéis. De acordo com Vieira e Silva, (2012, p.63),

o romance possui qualidades que revelam o orgulho do escritor de ter vivenciado, efetivamente, no feudo cacaueiro da Bahia, o martírio dos trabalhadores, a fim de dar credibilidade a todas as situações de miséria e exploração sofridas pelos empregados das fazendas.

A começar pela figura de Mané Frajelo, que muito assemelha-se com a do tio de Sergipano. É um explorador da classe trabalhadora. Não permite que seus funcionários consumam coisas que não sejam da venda da própria fazenda, as quais os preços não são 
mencionados e descontados diretamente do pagamento. Dessa forma, os trabalhadores vivem em constante dívida com o patrão, que faz com que os mesmos trabalhem por muito mais tempo a fim de pagá-la, um sistema de escravização por dívidas.

Um dos funcionários é acusado de deixar que o cacau mofasse. Despedido sem direito à indenização, foi obrigado a trabalhar para pagar o prejuízo. O empregado, então, foge da fazenda, mas outros dois funcionários vão ao seu encontro, por ordem do Coronel, e o espancam. Notoriamente, os funcionários o fizeram com medo de perderem seus empregos, já que, "a economia é uma manipulação invisível e múltipla que enlaça e prende indivíduos, grupos e conjuntos aos movimentos do dinheiro." (PIGLIA, 2009, p.107). Essa falta de consciência de sua própria classe e antipatia com seu igual é, de acordo com Gagnebin, (2006, p.96), "cruel e regressiva, porque implica que o sujeito não enfrenta o perigo, mas desiste de sua posição de sujeito, de sua identidade própria, para salvar a si próprio, perdendo a si mesmo."

Essa situação começou a despertar os questionamentos dos trabalhadores para saírem dela. Sergipano pergunta:

- Isso continuará sempre assim, Colodino?

Ele, de todos nós, parecia o único a ter uma certa intuição de que alguma coisa, um dia... - É impossível. Tem que mudar.

- Como?

- É o que não sei... (AMADO, 2010, I.982)

Através do romance de Jorge Amado, percebemos que "muitas vezes, o próprio relato de um complô faz parte do complô, e assim temos uma relação concreta entre narração e ameaça." (PIGLIA, 2009, p.97). Em outras palavras, o relato sobre as formas de 
exploração sobre o proletariado, seja na fábrica ou nos cacaueiros, faz parte do próprio complô contra esse tipo de exploração, já que "é ao redor da noção de maquinação que o romance constitui sua eficácia" (PIGLIA, 2009, p.99). Dessa forma, "o sujeito sente-se manipulado socialmente por certas forças, às quais atribui as características de uma conspiração destinada a controlá-lo e, portanto, deve armar um complô para resistir ao complô". (Ibidem, p.100)

Outra instituição abordada por Jorge Amado é a igreja e suas influências. Contam a Sergipano a notícia de um pai que assassinou filha e genro porque ambos eram casados apenas no registro civil e tiveram relações sexuais antes do casamento religioso. Uma crítica do autor ao movimento Integralista, que defendia uma forma de governo ligado a princípios que consideram éticos, religiosos e morais. Os trabalhadores, porém, começam a perceber falhas no sistema em que vivem:

- Tudo isso é ignorância - respondi - na minha terra os padres dominam tudo.

- Padre dá até azar. (AMADO, 2010, I.340)

No emblemático capítulo intitulado Consciência de Classe, Honório, colega de Sergipano - é chamado pelo Coronel para que matasse um dos funcionários da fazenda, seu também colega Colodino. Honório erra o tiro propositalmente e, ao ser questionado sobre o porquê daquilo, responde: "- Eu gostava de Colodino... Mas eu não queimei o bruto porque ele era alugado como a gente. Matá coroné é bom, mas trabaiadô não mato. Não sou traidô..." (AMADO, 2010, I.1371). A atitude de Honório leva Sergipano à seguinte reflexão: "Só muito tempo depois soube que o gesto de Honório não se chamava generosidade. Tinha um nome muito mais bonito: Consciência de Classe." (Ibidem). 
Sergipano também não era um traidor. Apaixonou-se por Mária, filha de Mané Frajelo. Como solução para que ficassem juntos, Mária propõe que o protagonista se torne patrão, pois seu pai o daria terras. Sergipano propõe o oposto: afirma que continuará trabalhando e que ela poderia virar mulher de alugado, o que ela rejeita prontamente. No capítulo seguinte, intitulado de "Amor", o protagonista tem a seguinte reflexão:

Olhei sem saudades para a casa-grande. $\mathrm{O}$ amor pela minha classe, pelos trabalhadores e operários, amor humano e grande, mataria o amor mesquinho pela filha do patrão. Eu pensava assim e com razão. (AMADO, 2010, I.1518).

Vai, então, para São Paulo, lugar em que seus amigos afirmavam que havia luta de classes. Para Sergipano, a consciência de classe era seu primeiro amor, capaz de subverter as condições de exploração.

\section{CONCLUSÃO:}

A narrativa literária de um determinado momento histórico e como lugar de pautas de minorias tem a função de fazer lembrar para que atos de violência e exploração não voltem a se repetir de formas distintas. "A ressalva é essencial: não há repetições na História, mas sim retomadas e variações que podem ser cruéis mesmo que sejam diferentes." (GAGNEBIN, 2006, p.104)

Portanto, é notável o compromisso ético da literatura e sua narrativa dotada de catarse, capaz de dar a ver determinadas situações e proporcionar transformações, ainda que pequenas, no mundo. De acordo com Sartre (2004, p.53):

a arte da prosa é solidária com o único regime onde a prosa conserva um sentido: a democracia. Quando uma é ameaçada, a outra também é. E não basta defendê-las com a pena. 
Chega um dia em que a pena é obrigada a deter-se, e então é preciso que o escritor pegue em armas. Assim, qualquer que seja o caminho que você tenha seguido para chegar a ela, quaisquer que sejam as opiniões que tenha professado, a literatura o lança na batalha; escrever é uma certa maneira de desejar a liberdade; tendo começado, de bom grado ou à força você estará engajado.

\section{REFERÊNCIAS}

AMADO, Jorge. Cacau. Versão eBook Kindle. Rio de Janeiro: Companhia das Letras, 2010. Não paginado.

ASSMANN, Aleílda. Espaços da recordação - formas e transformações da memória cultural. In:_.História, Memória, Literatura - O Testemunho na Era das Catástrofes. São Paulo: Editora Unicamp, 2006.

GAGNEBIN, Jeanne Marie. "Após Auschwitz". In: _. Lembrar Escrever Esquecer. São Paulo: Editora 34, 2006.

JAUSS, Hans Robert. A história da literatura como provocação à teoria literária. Trad. Sérgio Tellaroli. São Paulo: Ática, 1994.

Disponível em: https://ufprbrasileiraluis.files.wordpress.com/2015/02/jauss-arquivo-melhor.pdf Acesso em: 19/07/2017

PIGLIA, Ricardo. Teoria do complô. In: Serrote, na 2. São Paulo: Instituto Moreira Salles, julho de 2009.

SARTRE, Jean-Paul. Que é a Literatura? São Paulo: Editora Ática, 2004.

SELIGMANN-SILVA, Márcio. Reflexões sobre a memória, a história e o esquecimento. In:_. História, Memória, Literatura - O Testemunho na Era das Catástrofes. São Paulo: Editora Unicamp, 2006.

O testemunho: entre a ficção e o "real". In: SELIGMANN-SILVA, Márcio. História, Memória, Literatura - O Testemunho na Era das Catástrofes. São Paulo: Editora Unicamp, 2006.

VIEIRA, Denise Adélia; SILVA, Terezinha V. Zimbrão da. Jorge Amado e o romance proletário. In:_.Todas as Musas. São Paulo: Editora Todas as Musas, 2012. 
Disponível em: http://www.todasasmusas.org/04_01.htm.

Acesso em:11/08/2017

Artigo recebido em: 08 de fevereiro de 2018. Artigo aprovado em: 06 de setembro de 2018. 